Case Reports in
Gastroenterology
Case Rep Gastroenterol 2020;14:409-414

DOI: 10.1159/000508908
Published online: July 30, 2020

(C) 2020 The Author(s)

Published by S. Karger AG, Basel www.karger.com/crg

This article is licensed under the Creative Commons Attribution-NonCommercial 4.0 International License (CC BY-NC) (http://www.karger.com/Services/OpenAccessLicense). Usage and distribution for commercial purposes requires written permission.

\title{
Gastric Outlet Obstruction due to Malposition of Gastrostomy Tube: A Rare and Commonly Misdiagnosed Condition
}

\author{
Jamil Shah $^{\mathrm{a}}$ Abul Shahidullah ${ }^{\mathrm{b}}$ \\ aDivision of Gastroenterology and Hepatology, Department of Internal Medicine, The \\ Brooklyn Hospital Center, Academic Affiliate of The Icahn School of Medicine at Mount \\ Sinai, Clinical Affiliate of The Mount Sinai Hospital, Brooklyn, NY, USA; b Department of \\ Medicine, Henry J. Carter Specialty Hospital and Nursing Facility, New York, NY, USA
}

\section{Keywords}

Gastric outlet obstruction - Gastrostomy tube - Percutaneous endoscopic gastrostomy (PEG) · Complications of PEG

\begin{abstract}
Nearly all disease processes worsen with malnutrition. However, providing adequate and optimal nourishment can be challenging in individuals who are not able to eat. Insertion of a gastrostomy tube is a well-established method for providing enteral access for long-term nutritional support. Although enteral tube feedings are generally well tolerated, gastrostomy tube placement is associated with several complications. An uncommon, and often initially misdiagnosed, complication of gastrostomy tube placement is gastric outlet obstruction (GOO), which refers to the clinical outcome of any disease process that mechanically obstructs gastric emptying. $\mathrm{GOO}$ is a clinical syndrome characterized by nausea, postprandial nonbilious vomiting, epigastric pain, early satiety, abdominal distention, and insidious weight loss due to mechanical obstruction in the distal stomach, pylorus, or duodenum. Rarely, migration and malposition of a gastrostomy tube can lead to this condition. Therefore, physicians should be aware of $\mathrm{GOO}$ as a rare complication of gastrostomy tube placement. Often, simple adjustment of the tube can lead to rapid improvement and resolution of the patient's clinical condition as
\end{abstract}




\section{Case Reports in Gastroenterology}

Shah and Shahidullah: Gastric Outlet Obstruction due to Malposition of Gastrostomy Tube

well as prevent needless medical tests, overly aggressive management, and further complications. Here, we present an interesting case of a woman who developed a GOO after unintended migration of a gastrostomy tube.

(C) 2020 The Author(s)

Published by S. Karger AG, Basel

\section{Introduction}

On June 12,1979, the first percutaneous endoscopic gastrostomy (PEG) procedure was performed at the University Hospitals Rainbow Babies and Children's Hospital (Cleveland, $\mathrm{OH}$, USA) by pediatric surgeon Dr. Michael Gauderer, endoscopist Dr. Jeffrey Ponsky, and surgical resident Dr. James Bekeny [1]. The procedure was performed on a $4 \frac{1}{2}$-month-old infant with inadequate oral intake. The authors of the original technique, Drs. Gauderer and Ponsky, published it the following year as a technique to produce a sutureless gastrostomy in pediatric patients [1]. Since then, PEG has become widely performed with $160,000-200,000$ procedures performed annually in the USA [2].

Although success rates for PEG exceed 95\%, procedure-related complications are not uncommon [3-6]. A large meta-analysis that evaluated the effectiveness and safety of gastrostomy tube placement reported a major complication rate for PEG of $9.4 \%$ and a 30 -day procedure-related mortality rate for PEG of $0.53 \%$ [7]. Most series related to PEG tube placement have reported morbidity rates varying between 9 and 17\%, although major complications transpired in only $1-3 \%$ of cases $[8,9]$.

Furthermore, the lack of evidence for enteral tube feedings, especially among older adults with dementia, with regard to preventing aspiration pneumonia, improving functional status, enhancing quality of life, and prolonging survival, in addition to the potential for multiple complications of gastrostomy tube placement, have decreased the eagerness to perform this procedure for long-term nutritional support [10]. Here, we present an interesting case of a woman with a gastrostomy tube who developed a gastric outlet obstruction (GOO).

\section{Case Presentation}

A 55-year-old woman, living in a nursing home, had a past medical history of stroke, poststroke dysphagia with PEG tube placement, hypertension, diabetes mellitus, and chronic respiratory failure (with tracheostomy and oxygen delivered by Venturi mask). She received nutrition via enteral tube feedings. The PEG tube had been placed several months earlier and it was functioning well. However, for the past week, she had been experiencing intermittent nonbilious vomiting, usually after the tube feedings. Her medications consisted of amlodipine, metoprolol, insulin, and aspirin.

The patient was examined by the nursing home physician. She appeared comfortable and was in no distress. Consistent with her baseline, she was awake, noncommunicative, and did not respond to verbal stimuli. She was hemodynamically stable (heart rate 96 beats/min, blood pressure $150 / 85 \mathrm{~mm} \mathrm{Hg}$ ), afebrile (temperature $36.6^{\circ} \mathrm{C}$ ), and had a respiratory rate of 20 breaths/min. On physical exam, a tracheostomy was present, and the patient was breathing comfortably with oxygen delivered by Venturi mask. The abdomen was soft and not distended with no tenderness and normoactive bowel sounds. There was no organomegaly. There was no guarding or rigidity.

The gastrostomy site was clean, dry, intact, and free of erythema, drainage, and exudate (Fig. 1). However, the tube had migrated into the abdomen up to the $18-\mathrm{cm}$ mark at the skin 


\section{Case Reports in Gastroenterology}

Case Rep Gastroenterol 2020;14:409-414 DOI: $10.1159 / 000508908$

(c) 2020 The Author(s). Published by S. Karger AG, Basel www.karger.com/crg

Shah and Shahidullah: Gastric Outlet Obstruction due to Malposition of Gastrostomy Tube

level. Moreover, there was resistance to attempts to reposition the tube percutaneously, and it could not be easily moved inward or outward.

A plain abdominal X-ray was unremarkable. Laboratory testing, consisting of a CBC, BMP, LFTs, amylase, and lipase, was unremarkable. The patient was evaluated by a gastroenterologist who ordered an Omnipaque ${ }^{\mathrm{TM}}$ contrast study of the gastrostomy tube, which revealed contrast extrusion into the duodenum but no contrast in the stomach (Fig. 2a). The inflated internal balloon of the gastrostomy tube had migrated distally and become trapped in the duodenum, thus causing a functional GOO and duodenal obstruction. Therefore, the internal balloon of the tube was deflated, the tube was repositioned by pulling back and withdrawing it into the stomach, the internal balloon was inflated again, and the tube was secured to the abdominal wall with the external retainer at the $3.5-\mathrm{cm}$ mark. A repeat Omnipaque ${ }^{\mathrm{TM}}$ contrast study revealed contrast in the stomach and the duodenum, confirming the location of the distal tip of the gastrostomy tube in the stomach (Fig. 2b). Enteral tube feedings were resumed, and the patient tolerated them with no difficulty.

\section{Discussion}

Among patients with gastrostomy tubes, a common reason for visits to the emergency department is tube dislodgment, with an incidence ranging from 4 to 13\% [11]. This complication frequently occurs in confused and combative patients. There may be accidental or excessive pulling of the tube, or the tube may not be adequately secured. Furthermore, gastric motility, or the contractions of gastric smooth muscle, and strong peristaltic waves of contraction exert pulling and pushing forces all the time on the gastrostomy tube bumper or balloon. The displacement can happen externally or internally. When displaced internally, the bumper or balloon can migrate into the pyloric channel or duodenal bulb and cause GOO.

The incidence of GOO is not precisely known. In 1990, as many as 2,000 surgical procedures to treat GOO, caused by any disease process, were performed in the USA each year [12]. However, the incidence of GOO has gradually decreased with the discovery of Helicobacter pylori, the introduction of proton pump inhibitors, and the subsequent decline of peptic ulcer disease - previously an important cause of GOO [13]. Updated estimates are not available, but, due to advancements in endoscopic methods of treating GOO (such as dilation and stenting), the need for surgery has decreased as well [13].

Risk factors for GOO in individuals with a gastrostomy tube include insertion of the gastrostomy tube such that the internal bumper or balloon is close to the pylorus $[14,15]$. Also, if an external retainer is present but migrates away from the abdominal wall, the tube can slide forward through the gastrostomy tract and into the duodenum, thus causing a GOO. Irrespective of the type of gastrostomy tube (whether it is of the bumper or balloon type), if the inflated internal balloon or internal bumper is allowed to migrate through the pylorus, it can cause mechanical obstruction (Fig. 3). This complication can be avoided by confirming that the external retainer is appropriately positioned.

In summary, delayed recognition of malposition of the gastrostomy tube can be catastrophic for the patient. Physicians should be aware of the symptoms and signs of gastrostomy tube malposition and, if needed, order appropriate diagnostic studies such as contrast studies and abdominal X-rays. Thus, early recognition and treatment of the complication of GOO is crucial. Prompt and safe management can lead to rapid improvement and resolution of the patient's clinical condition. 


\section{Case Reports in Gastroenterology}

\begin{tabular}{l|l}
\hline DOI: $10.1159 / 000508908$ & (c) 2020 The Author(s). Published by S. Karger AG, Basel \\
\hline
\end{tabular}
www.karger.com/crg

Shah and Shahidullah: Gastric Outlet Obstruction due to Malposition of Gastrostomy Tube

\section{Statement of Ethics}

The guardian of the patient presented in this case report gave written informed consent to publish the case (including publication of images).

\section{Disclosure Statement}

The authors have no conflicts of interest to declare.

\section{Funding Sources}

The authors of this case report declare that no financial support or grant support has been received for the preparation of this manuscript.

\section{Author Contributions}

A.S. conceived of the idea for the manuscript. J.S. designed and drafted the manuscript. A.S. and J.S. evaluated and critically revised the manuscript for important intellectual content. A.S. provided the images. Both authors approved the final version of the manuscript.

\section{References}

1 Gauderer MW, Ponsky JL, Izant RJ Jr. Gastrostomy without laparotomy: a percutaneous endoscopic technique. J Pediatr Surg. 1980 Dec;15(6):872-5.

2 Potack JZ, Chokhavatia S. Complications of and controversies associated with percutaneous endoscopic gastrostomy: report of a case and literature review. Medscape J Med. 2008 Jun;10(6):142.

3 Larson DE, Burton DD, Schroeder KW, DiMagno EP. Percutaneous endoscopic gastrostomy. Indications, success, complications, and mortality in 314 consecutive patients. Gastroenterology. 1987 Jul;93(1):48-52.

4 Gibson SE, Wenig BL, Watkins JL. Complications of percutaneous endoscopic gastrostomy in head and neck cancer patients. Ann Otol Rhinol Laryngol. 1992 Jan;101(1):46-50.

5 Pender SM, Courtney MG, Rajan E, McAdam B, Fielding JF. Percutaneous endoscopic gastrostomy-results of an Irish single unit series. Ir J Med Sci. 1993 Nov;162(11):452-5.

6 Wilson WR, Hariri SM. Experience with percutaneous endoscopic gastrostomy on an otolaryngology service. Ear Nose Throat J. 1995 Nov;74(11):760-2.

7 Wollman B, D’Agostino HB, Walus-Wigle JR, Easter DW, Beale A. Radiologic, endoscopic, and surgical gastrostomy: an institutional evaluation and meta-analysis of the literature. Radiology. 1995 Dec;197(3):699-704.

8 Lin HS, Ibrahim HZ, Kheng JW, Fee WE, Terris DJ. Percutaneous endoscopic gastrostomy: strategies for prevention and management of complications. Laryngoscope. 2001 Oct;111(10):1847-52.

9 DiSario JA. Endoscopic approaches to enteral nutritional support. Best Pract Res Clin Gastroenterol. 2006;20(3):605-30.

10 Callahan CM, Haag KM, Weinberger M, Tierney WM, Buchanan NN, Stump TE, et al. Outcomes of percutaneous endoscopic gastrostomy among older adults in a community setting. J Am Geriatr Soc. 2000 Sep;48(9):1048-54.

11 Rosenberger LH, Newhook T, Schirmer B, Sawyer RG. Late accidental dislodgement of a percutaneous endoscopic gastrostomy tube: an underestimated burden on patients and the health care system. Surg Endosc. 2011 Oct;25(10):3307-11.

12 Gibson JB, Behrman SW, Fabian TC, Britt LG. Gastric outlet obstruction resulting from peptic ulcer disease requiring surgical intervention is infrequently associated with Helicobacter pylori infection. J Am Coll Surg. 2000 Jul;191(1):32-7. 


\section{Case Reports in Gastroenterology}

\begin{tabular}{l|l}
\hline Case Rep Gastroenterol 2020;14:409-414 \\
\hline DOI: 10.1159/000508908 & $\begin{array}{l}\text { @ 2020 The Author(s). Published by S. Karger AG, Basel } \\
\text { www.karger.com/crg }\end{array}$ \\
\hline
\end{tabular}

Shah and Shahidullah: Gastric Outlet Obstruction due to Malposition of Gastrostomy Tube

13 Storm AC, Ryou M. Advances in the endoscopic management of gastric outflow disorders. Curr Opin Gastroenterol. 2017 Nov;33(6):455-60.

14 Barosa R, Santos C, Fonseca J. Gastric outlet obstruction: an unusual adverse event of percutaneous endoscopic gastrostomy. Rev Esp Enferm Dig. 2016 Jan;108(1):53-4.

15 Caners C, Bhurwal A, Rahni D. Tube migration leading to gastric outlet obstruction: an unusual complication of percutaneous endoscopic gastrostomy. J Med Cases. 2017 Dec;8(12):407-8.
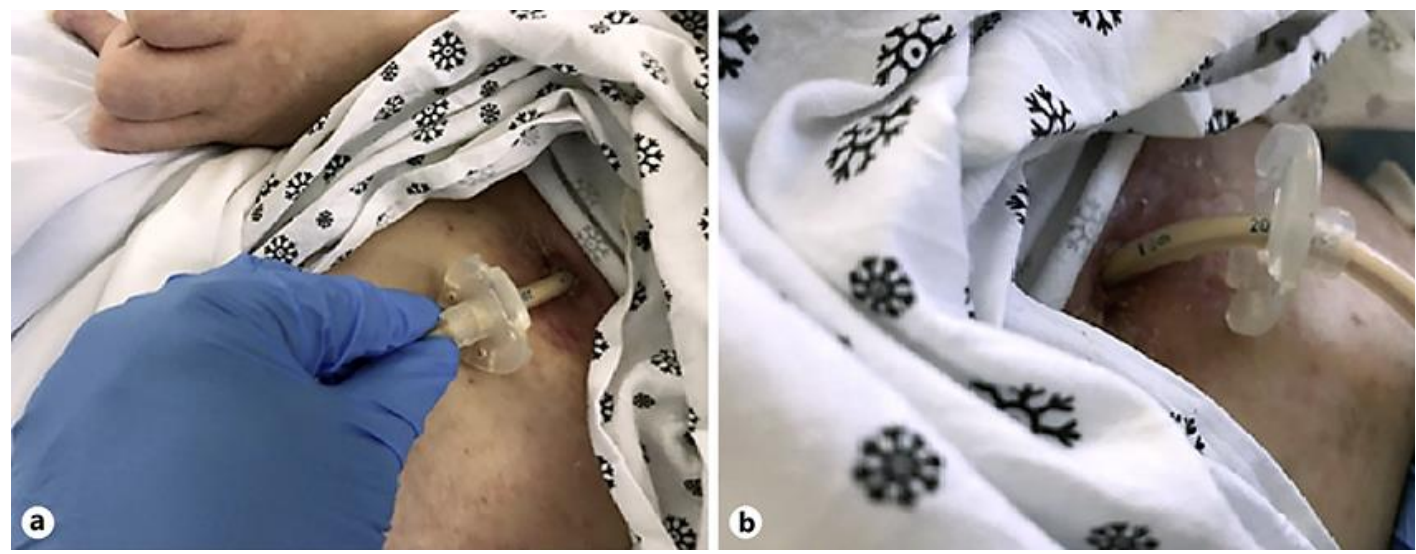

Fig. 1. a, b The gastrostomy site is clean, dry, intact, and free of erythema, drainage, and exudate. The tube has migrated into the abdomen. The $18-\mathrm{cm}$ mark at the skin level is visible.
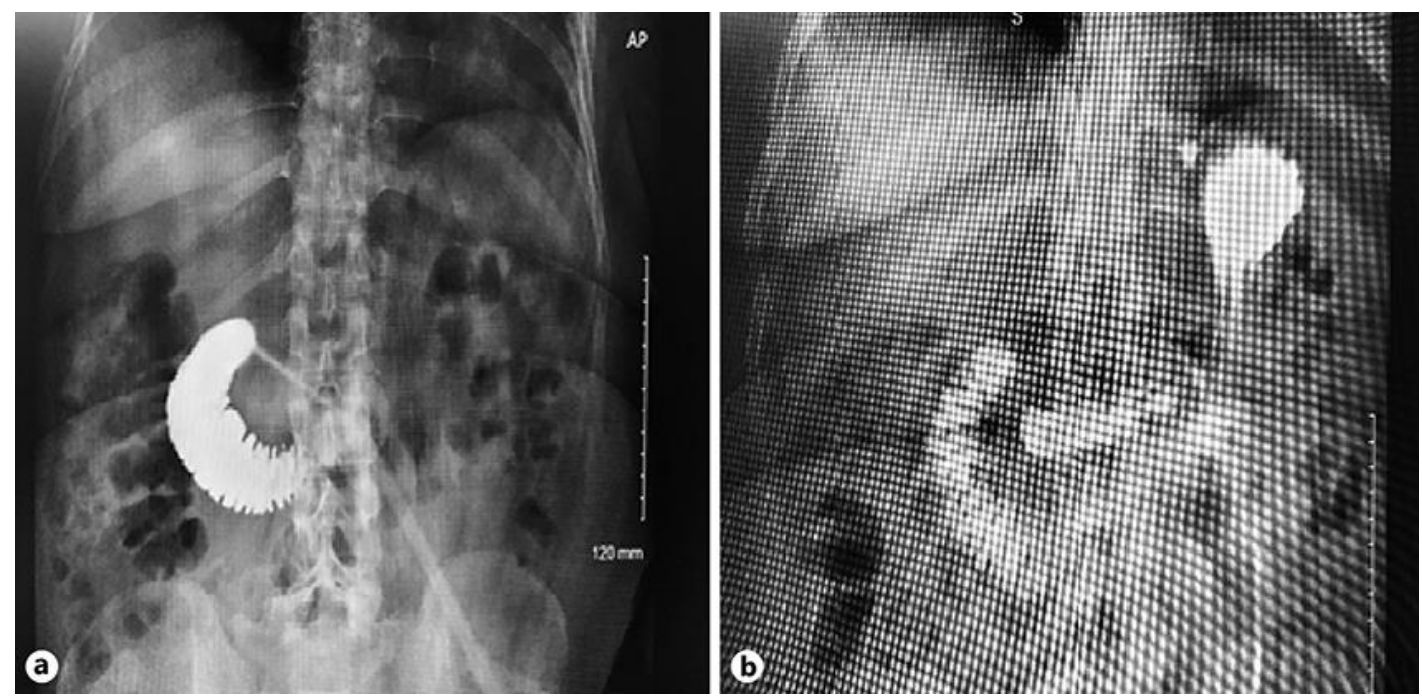

Fig. 2. a, b Omnipaque ${ }^{\mathrm{TM}}$ contrast studies and abdominal X-rays, before and after repositioning of the gastrostomy tube. a There is contrast extrusion into the duodenum but no contrast in the stomach. The inflated internal balloon of the gastrostomy tube has migrated distally and become trapped in the duodenum, thus causing a functional GOO and duodenal obstruction. $\mathbf{b}$ There is contrast in the stomach and the duodenum, confirming the location of the distal tip of the gastrostomy tube in the stomach. 
Case Reports in Gastroenterology
Case Rep Gastroenterol 2020;14:409-414

DOI: 10.1159/000508908

(c) 2020 The Author(s). Published by S. Karger AG, Basel www.karger.com/crg

Shah and Shahidullah: Gastric Outlet Obstruction due to Malposition of Gastrostomy Tube
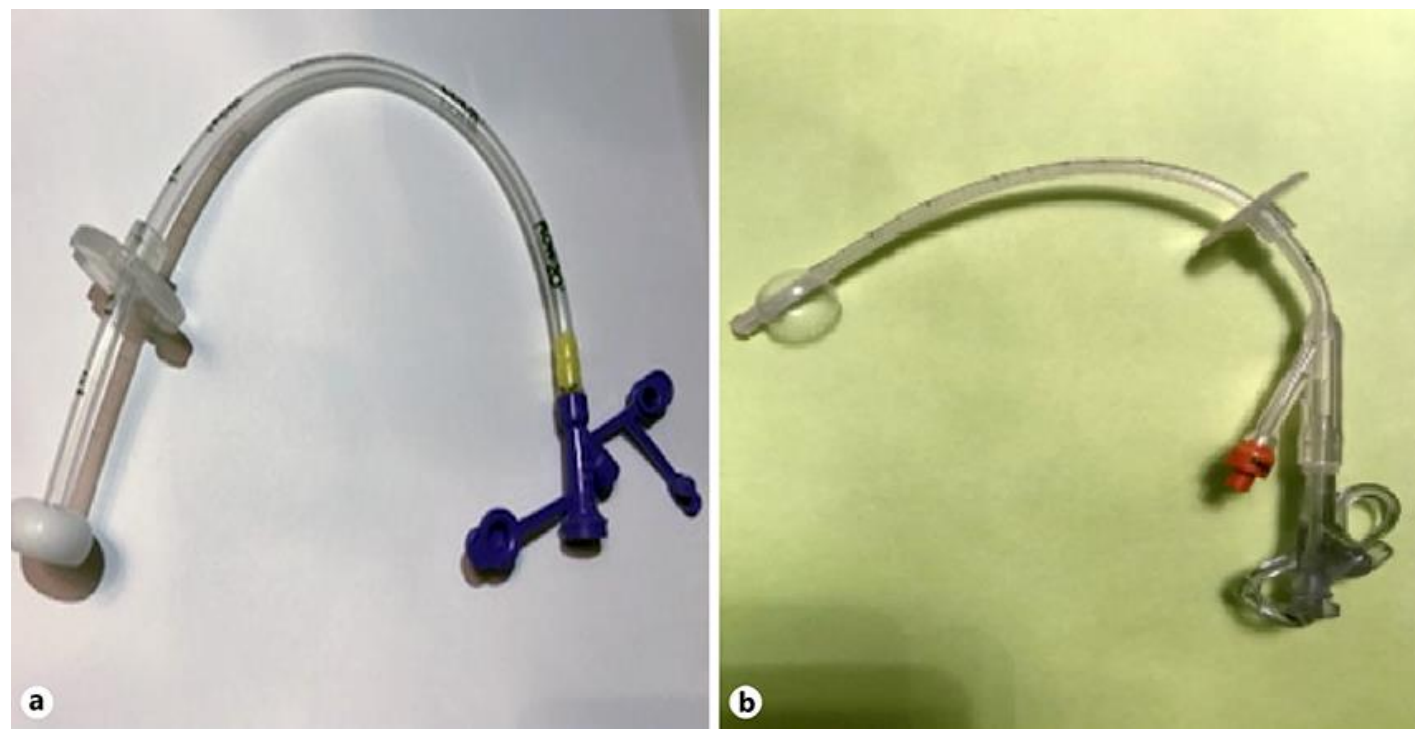

Fig. 3. a The bumper type of gastrostomy tube. $\mathbf{b}$ The balloon type of gastrostomy tube. During tube placement, a gastrocutaneous tunnel is created and a tube with either an internal bumper or an internal balloon is inserted. The bumper or inflated balloon remains in the stomach to prevent the expulsion of the gastrostomy tube. The external retainer keeps the bumper or balloon in close contact with the inside wall of the stomach and helps to keep the abdominal and stomach walls in apposition for future formation of a mature track. 